Научная статья

УДК 177.5

DOI: $10.18101 / 1994-0866-2021-2-48-60$

\title{
ПОЛИТИКА И МЕТОД ИНТЕЛЛЕКТУАЛЬНОЙ ЭМАНСИПАЦИИ
}

\author{
(C) Власов Александр Александрович \\ аспирант, \\ Российский государственный гуманитарный университет \\ Россия, 125993, г. Москва, Миусская площадь, 6 \\ mioxin@gmail.com
}

\begin{abstract}
Аннотация. Статья посвящена анализу работы Жака Рансьера «Невежественный наставник», в которой автор обращается к педагогическому опыту французского преподавателя Жозефа Жакото. В своей работе Рансьер не просто предлагает читателю критический взгляд на методику традиционного образования, но, выходя за рамки чисто педагогической плоскости, развивает идеи Жакото и переносит их в сферу общественно-политических отношений, показывая, как не только сама школа воспроизводит зависимое положение ученика от учителя, но и государство, посредством привычной стратегии образования, поддерживает устоявшийся общественный порядок, притупляя и сводя на нет индивидуальный потенциал каждого гражданина (таким же образом, как при помощи «объяснения» это делает «знающий» наставник с «необразованным» учеником).

В своей провокационной критике Рансьер (вместе с Жакото) пытается продемонстрировать возможность существования иного рода отношений между учителем и учеником, когда каждый из них находится на равной дистанции от источника знания. И, обнажая потенциал «невежественного» наставника, Рансьер стремиться выйти на новый уровень прочтения отношений между ними осмыслить само общество, внутри которых действуют эти моральные агенты.

Ключевые слова: Рансьер, Жакото, либертарная педагогика, универсальное обучение, общественный порядок, государство
\end{abstract}

\section{Для цитирования}

Власов А. А. Политика и метод интеллектуальной эмансипации // Вестник Бурятского государственного университета. Философия. 2021. Вып. 2. С. 48-60.

\section{Введение}

В 2021 г. исполняется 34 года с момента первой публикации работы Жака Рансьера «Le Maître ignorant: Cinq leçons sur l'émancipation intellectuelle» («Невежественный наставник: пять уроков об интеллектуальной эмансипации». - nер. А.), которая до сих пор остается не переведенной на русский язык несмотря на существенный резонанс, вызванный этой книгой в далеком 1987 г.

В своей работе Рансьер обращается к образованию, понимаемому как закрытый продукт, упакованный, предсказуемый, измеримый, как если бы это был качественный процесс промышленного производства, отмечая, что такая трактовка образования не только не соответствует реальности человеческого обучения, но и не приспосабливается к образовательным потребностям нашего 
времени, поскольку современная динамика требует не затвердевших истин, но развивающихся знаний, творчества и инноваций.

Вместе с этим «Невежественный наставник» развивается в двойном регистре, двумя параллельными путями, которые пересекаются и имеют обратную связь. Первое направление представляет собой историю Жозефа Жакото (1770-1840) и его личного опыта преподавания на заре XIX в., глубоко потрясенного рядом случайных обстоятельств, которые привели к резкому изменению его взглядов на традиционное образование. Вторая линия повествования разворачивается на основе политического присвоения Рансьером этого опыта. В этом двойном движении книга накладывает на основополагающее описание педагогического вопроса построение сугубо политической проблемы, по сути истинного ядра работы.

Стоит отметить, что именно это движение от педагогического к политическому вызывает особый интерес по причине того, что в своем большинстве работы по либертарной педагогике (Вард, Феррер, Фор, Ленуар и др.) рассматривают педагогику как конечную цель воспитания «нового сознания», в то время как для Рансьера отношения, заложенные в базу образовательного процесса, выступают отправной точкой его критического анализа. В связи с этим, цель настоящей статьи видится в попытке пролить свет на систему установленных и воспроизводящих друг друга иерархических отношений как в рамках образовательного процесса, так и в контексте общества в целом. Иными словами (подобно самому Жозефу Жакото), показать возможность существования иного рода отношений между теми, кто знает, и теми, кто - нет.

Случайность

Уникальность опыта Жакото объясняется тем, что, будучи приглашенным для преподавания французского языка в Нидерланды, он столкнулся с двойной проблемой: сам он не владел голландским языком, но также и его новые студенты не имели ни малейшего представления о французском языке. И, несмотря на кажущуюся безысходность ситуации, ему удалось добиться удивительного результата - через несколько недель все выучили французский язык.

То, что произошло с Жакото, было случайностью, следствием конкретной ситуации, контекста, который не позволял ему применить традиционную педагогику - метод, который он обычно использовал со своими учениками. Жакото был прогрессивным учителем, сыном Просвещения и Революции. Он был далек от типичного «тупого учителя, который наполняет головы своих учеников неудобоваримым знанием, или зловредного существа, которое использует двойную истину, чтобы гарантировать свою власть и социальный порядок» [1 p. 9]. До этого времени он верил в то, во что верили все сознательные учителя: великая задача учителя - передать свои знания своим ученикам, чтобы постепенно возвысить их до уровня их собственной науки. Как и они, он знал, что дело не в том, чтобы набить учеников знаниями или заставить их повторять, как попугаев, но он также знал, что необходимо избегать тех 
случайностей, где теряются души, которые все еще не способны отличить главное от сущего и принцип от последствия $[1, \mathrm{p} .6]$.

Но шанс бросил вызов его многолетнему опыту и поставил под сомнение основу всей педагогики: объяснение. Без общего языка невозможно было объяснить, потому что не было способа сделать свое объяснение доступным. Следовательно, если Жакото все еще должен был играть роль учителя, то эта задача более не могла основываться на объяснении своих знаний ученикам.

Необходимость вынудила его полностью исключить из игры свой интеллект, тот опосредующий интеллект учителя, который связывает интеллект, записанный в письменных словах, с интеллектом ученика. И в то же время он подавил эту воображаемую дистанцию, которая является началом педагогического оцепенения [1, p. 10].

У студентов Жакото не было иного выхода, как учиться без объясняющего учителя. То есть они учились независимо, каждый имел в своем распоряжении свои средства собственного интеллекта. Таким образом, можно сказать, что Жакото превратил свои ограничения в преимущество: случайно он нашел ключи к методу обучения, который сталкивал ученика с его собственными ограничениями, но который также и использовал лучшее в ученике с тем, чтобы преодолеть их. Интеллект, который заставил их изучать французский язык, был тем же самым, с которым они изучали свой родной язык: наблюдение и запоминание, повторение и проверка, соотнесение того, что они якобы знали, с тем, что они знали до этого, действие и размышление о том, что они сделали. Они сделали то, чего не следует делать, как делают дети, прокладывая путь вслепую, идя наугад [1, p. 10].

\section{Объяснение}

«Невежественный наставник» c самых первых страниц направляет разрушительную атаку на классический и знаковый ресурс всего образования: объяснение. Внезапно мы видим, как объяснение превращается из привилегированного инструмента, с помощью которого учителя самоотверженно пытались вести своих учеников к знаниям и культуре, в тонкое оружие навязывания и господства. Ряд конкретных обстоятельств его личного опыта преподавания заставил Жакото понять, что «объяснение» (то есть поэтапное продвижение учеников от незнания к знанию) противоречит тому, чего придерживается педагогика. До этого момента никто не представлял, что между учителями и учениками можно было построить другие отношения, отличные от традиционных вертикальных, построенные на основании того, кто якобы знает, и того, кто не знает. Это ошеломляющее открытие, возникшее в ходе практики, стало переломным моментом всей концепции обучения и изменило жизнь Жакото в стремлении раскрыть до конечных последствий ту новую модель отношений, которую он обнаружил. С другой стороны, сам Рансьер деликатно задерживает внимание на этом процессе и, в свою очередь, раскрывает во всех масштабах те политические последствия, которые влечет за собой этот излом традиционного порядка.

В интерпретации Жакото - Рансьера объяснение выполняет фундаментально регулирующую задачу. Поскольку именно оно делит мир на две части, отделяя 
тех, кто знает, от тех, кто не знает - тех, кто «объясняет», от тех, кто слушает и «учится», - объяснение устанавливает дифференциацию, которая гораздо более значима, чем простое различие между областями знаний. Все классическое обучение основывается на этой предположительно нейтральной идее о передаче объяснения, матрица которой утверждает в широком смысле, что есть что-то (знание, навык), которым кто-то - учитель - обладает, и передает это посредством объяснения тому, у кого его нет, - ученику. Тот, кто не знает, учится понемногу и со временем приобретает знания, которых ему не хватало. Но признание этого различия между теми, кто знает, и теми, кто не знает, которое присуще самому существованию любого учения, не только определяет отношения, которые каждый имеет со знанием, но и, что самое важное, оно разграничивает ряд социальных слоев. Фактически осознание этого дробления, производимого обладанием определенного знания, заставляет каждого усвоить занимаемое место и увидеть, что возможность роста связана с подчинением - в основном интеллектуальным - тому, кто объясняет. Но, если бы можно было делать это самому, в учителе не было бы необходимости.

Согласно Жакото, образовательное учреждение выполняет функцию воспроизведения этого иерархического различия, потому что на нем основано само существование института образования, это условие самой возможности к его существованию. Учитель от имени государства управляет сегментом власти. Он контролирует расстояние между тем, чему следует учить, и тем, что изучено, между тем, чему можно научить, и пониманием того, чему учат: «Искусство педагогики - это искусство бесконечно воспроизводить дистанцию, то есть неравенство, которое она стремится подавить» [2, p. 14]. Именно учитель в этой связи представляет собой надзор и гарантию эффективности передачи. Тот, кто что-то объясняет, а затем контролирует точность того, что «изучено», для Жакото является «производителем отупления» (фр. abrutissant), тем, кто не освобождает, а помещает другого в мир каст, утвержденный и естественный.

Для чего они нужны, если можно учиться без них? - задается вопросом Рансьер в прологе к книге Жакото La enseñanza Universal. La lengua Materna. И его ответ ошеломляет: «Объяснения не служат для того, чтобы научить ученика тому, чему он не смог бы научиться без них; они предназначены для того, чтобы научить его тому, что без них он не мог бы учиться, они служат, чтобы научить его собственной неспособности» [2, p. 13].

Объяснить что-то кому-то - значит показать ему, что он сам этого не понимает. Жакото непреднамеренно порвал с логикой всей педагогики, которая стремится преодолеть разрыв между тем, кто знает, и тем, кто не знает, посредством передачи знания, либо посредством объяснения, либо посредством метода Сократа. Он положил конец мифу о педагогике, мифу, который делит мир на два класса - мудрых и невежественных.

«Универсальное обучение»

Я верю, что Бог создал человеческую душу, способную обучать себя в одиночку и без учителя. Необходимо чему-то научиться впервые и все остальное связать в соответствии с этим принципом: все люди обладают равным 
интеллектом. Тот, кто не считает себя способным научить своего сына тому, чего он не знает, еще не понял меня [2, p. 23].

При использовании нового метода, который Жакото назвал «универсальным обучением», передачи знания не было. Учитель не передавал своим ученикам своих прежних знаний. Они учились самостоятельно, автономно, но это не значит, что они учились без наставника. При этом Жакото не отвергает фигуру учителя, но, скорее, признает иную роль, которую тот должен играть в образовательном процессе. Говоря современным языком, учитель это не поставщик контента при поддержке объяснений, но тот, кто способствует встрече ученика с новой информацией и оставляет их один-на-один. Он тот, кто заставляет их выживать в пределах круга ограниченных возможностей. Следовательно, учитель необходим. По крайней мере, на минимальном уровне вмешательства, чтобы сказать своим ученикам, что они могут это сделать, что они могут учиться самостоятельно. Учитель, таким образом, превращается в искру, которая зажигает обучающий фитиль и подталкивает учеников к интерпретации текста, лежащего перед ними. Да, его ученики хотели учиться. Без их воли ничего бы не произошло. И в этом свете воля - концепция, которая в последние десятилетия подвергалась сомнению и во многих случаях заменялась мотивачией [3], была и остается решающей.

Учитель Рансьера, Жакото предлагает нам пересмотреть роль учителя и ученика. Ни одна из двух фигур никогда не будет прежней. Биеста [4] отмечает, что фигура учителя излучает ауру превосходного интеллекта, чтобы стать волей: волей, требующей усилий ученика, подтверждающей их и сопровождающей их усилиями собственного обучения. В конце концов, мы могли бы говорить о сверстниках, о равных, которые сопровождаются непрерывным, жизненно важным, уникальным процессом обучения, которым также можно делиться.

Вскоре Жакото осмелился учить тому, чего он не знал, и высказал свое самое рискованное и интересное предложение: можно научить тому, чего не знаешь. Можно быть невежественным учителем. Его метод свободы был методом воли: кто хочет, тот может. Сегодня это можно было бы назвать расширением прав $u$ возможностей учащихся, которые способны присвоить собственное обучение, а также средств приобретения, производства и передачи знаний.

Таким образом, становится очевидным, что этот педагогический опыт вел к разрыву с логикой всей педагогики. Практика педагогов основана на противопоставлении науки и невежества. Педагоги различаются способами, выбранными для того, чтобы сделать невежественных знающими: жесткими или мягкими, традиционными или современными, пассивными или активными, но эффективность которых всегда можно сравнить. С этой точки зрения при первичном анализе можно было бы сравнить скорость учеников Жакото с медлительностью традиционных методов. Но на самом деле сравнение было невозможным. Противостояние методов предполагает минимальное согласование целей педагогического акта: передать знания учителя ученику. Однако Жакото ничего не передавал. Он не использовал никаких методов. Метод был исключительно исходящим от ученика. То есть сравнение не проводилось 
между методами, а между двумя видами использования интеллекта и между двумя концепциями интеллектуального порядка [1, p. 12].

\section{Эмансипатор}

Чему учит эмансипирующий учитель в отличие от другого, который объясняет и таким образом отупляет? В чем состоит это иного рода обучение? Жакото выделяет две функции, которые объединяет практика объясняющего учителя: функция знатока или специалиста по определенному знанию и функция обучающего. Что тогда может означать учить чему-то, кроме знания, быть кем-то другим, вместо знающего, передающего свои знания? Речь идет не о том, чтобы преподавать собственное знание (строго говоря, вам даже не нужно его иметь, в чем и заключается скандальная возможность «невежественного» учителя), а о том, чтобы четко указать на то, что другой способен научиться тому, чего сам пожелает. То, чему вы учитесь, когда освобождаетесь, - это использовать свой собственный интеллект. В этом отношении роль учителя будет заключаться в том, чтобы поставить ученика перед проблемой, из которой найти выход он сможет только самостоятельно. Это предполагает постановку вопросов на равных, а не с позиций знатока, который уже знает все ответы. Тот, кто учит, освобождая, знает, что он тоже учится, и ответы другого - это новые вопросы для него самого. Следовательно, слово циркулирует среди всех участников образовательного процесса, а не в одном направлении.

Это позволило бы каждому говорить не как учитель или ученик, но как человек. То есть не как тот, кого экзаменуют ради оценки, а как тот, кому интересно то, что он может сказать. Речь идет не об объяснении того, что говорят или делают ученые, художники или философы, но о том, чтобы быть в некотором роде учеными, художниками или философами.

Таким образом, Жакото встревожил академический мир своего времени, указав на то, что из провозглашения радикального равенства интеллекта и из интеллектуальной эмансипации низших классов, в принципе «лишенных» знаний, один невежественный человек был способен сделать так, чтобы другой невежественный мог получить доступ к этим знаниям без необходимости в посреднике для передачи их им, а, скорее, в прямом диалоге с источниками [5].

Однако для Рансьера, со своей стороны, опыт Жакото - это нечто большее. Он перестал быть отупляющим учителем, чтобы стать учителем-эмансипатором. Тот, кто эмансипирует, дает нам «не ключ к знанию, но осознание того, что может сделать разум, когда он считает себя равным любому другому и считает любого другого равным самому себе» [1 p. 25].

В этой связи для самого Рансьера конечной целью является не равенство, а именно его отправная точка. «Радикальность» Жакото заключалась не в стремлении к равенству интеллекта через образование, а в том, чтобы исходить из него (равенства) как из исходной посылки его педагогики: «Если я начал с того, чтобы дать понять, что я предполагаю равный интеллект у всех людей, то мой проект состоит в том, чтобы поддержать этот во что бы то ни стало» $[2$, p. 26]. 
В этом и заключается метод Жакото - он не претендует на то, чтобы быть установить, и никогда не пытается продемонстрировать педагогическую теорию: это опыт; это факт; это нечто, что работает.

Не будучи педагогической книгой, «Невежественный наставник» направляет мощное послание, которое лишь внешне противоречит здравому смыслу, преобладающему в нашей образовательной системе. Ее чтение ставит под сомнение роль школы, учителей и каждого из нас как учеников. С этой позиции это заставляет нас думать о таких инициативах, как Новая школа, Школа Саммерхилл, школа Френе, экспериментальные школы 1970-х гг., и прогрессивных педагогах, таких как Джон Дьюи, Франсиско Хинер де лос Риос или Мария Монтессори. Исследование книги приглашает нас к диалогу с Пауло Фрейре из «Педагогики угнетенных» и «Педагогики автономии» (Pedagogía del oprimido, Pedagogía de la autonomía), в которых автор заявляет, что «обучение это не передача знаний, а создание возможностей для их собственного производства или создания» [6, p. 47]. «Невежественный наставник» также соотносится с теориями отказа от школы, предложенными около 40 лет назад Куэрнавакским кружком (Círculo de Cuernavaca), Центром межкультурной документации (CIDOC), Иваном Илличем [7], Эвереттом Реймером, Полом Гудманом и Джоном Холтом [8].

«Невежественный учитель» Жак Рансьера напоминает нам, несмотря на различия, которые сам Рансьер сделал видимыми в своей книге, о прогрессивных методах педагогики и о конструктивистских и ориентированных на студентов ее видах первой половины XX в., суть которых сводится к манифесту Пиаже: главная цель образования - создать людей, способных делать что-то новое, а не просто повторять то, что сделали другие поколения; люди должны быть креативными, изобретателями и первооткрывателями [9].

\section{Политика}

Но все-таки, какое политическое толкование можно сделать об «антиобразовании» Жакото, который не уставал повторять, что ему нечему учить своих учеников? Возможность эмансипации в обучении связана, по мнению Жакото, с возможностью тройного вопрошания, что является либертарным призывом, направленным на разум, и радикальным императивом, направленным на волю [10, p. 303]. Учитель не должен переставать спрашивать: «А ты, что ты видишь? Что ты думаешь? Что бы ты сделал?». Тогда ответы перестанут быть тем секретом, которым дорожит учитель, чтобы стать для каждого ученика завоеванием знаний, мира и самого себя. Единственный императив, которого учитель должен держаться в отношении студента, - «Ты можешь!» Исходя из этого лозунга, расширяющего возможности каждого, вместе с тремя вышеупомянутыми вопросами можно переместить образовательный вопрос в сторону политики и оценить его последствия. В самом деле тот, кто не подчиняется иерархическому порядку, основанному на неравенстве интеллекта или иных критериях, тот, кто не считает себя неполноценным, но признает и ценит свои собственные способности и поддерживает себя в своем упорстве, сможет освободить себя. Рабочий (крестьянин, ремесленник или кто-либо другой) будет интеллектуально эмансипирован, «если он будет думать о том, что́ 
он есть и что он делает в рамках общественного строя» [1, p. 57]. Можно было бы сказать, что, строго говоря, только тогда он и становится субъектом - тем, кто знает себя как интеллектуального исследователя, как того, кто думает и может действовать соответственно. Поскольку именно такой человек, который задает себе вопросы, способен задавать вопросы тем, кто якобы знает, и, прежде всего, тем, кто не просто как бы знает, но также и управляет. В терминах Жакото: «Вся практика универсального обучения сводится к вопросу: а что думаешь ты? Вся сила такого обучения основывается на осознании интеллектуальной эмансипации, которое оно актуализирует в учителе и пробуждает в ученике» [1, p. 60].

Если речь идет не о передаче знаний, то может ли кто угодно стать освобождающим учителем? Безусловно, до тех пор, пока он использует технику тройного вопрошания и формулу «ты можешь».

Чтобы понять «Невежественного наставника» в его собственном измерении, мы должны начать с осознания того, что он задуман не как книга по педагогике, а как работа о демократии, равенстве и образовании [11, p. 93]. Книга, в которой не столько ставится под сомнение роль школы, несмотря на то, что государственное образование рассматривается как «средство постепенного выравнивания неравенства» или «устранение бесконечного равенства» [1, p. 71], поскольку оно исходит из нашего общества, но, превращая равенство в цель, оно лишь усиливает неравенство.

«Невежественный наставник» - это книга об интеллектуальной эмансипации, которая вместе с тем предупреждает о том, насколько наше общество подвержено педагогическому воздействию, об опасности жизни в условиях огромного механизма объяснения. Это критика мира, в котором доминируют самопровозглашенные эксперты, игнорирующие другие типы знания, другие способы познания и другие голоса. Это общество, где доминируют «влиятельные», которые действуют как педагоги, чтобы объяснить нам то, чего мы не знаем. Мир разделен на две части: те, у кого есть, и те, у кого нет; эксперты и непрофессионалы, — те, кто знает, и те, кто не знает.

Нетрудно увидеть анархистскую черту в основе политико-педагогического подхода, на который делает акцент Рансьер, обозревая метод Жакото: преподавание и обучение - это прямая связь между людьми (без посредничества), невозможность институционализации самого метода, конфликтные отношения с государством и т. д. Но возможная перспектива деконструкции школы, которая могла бы проистекать из общего подхода Жакото, не так интересна — поскольку намерение Рансьера больше политическое, чем педагогическое, - как возможность размышления с этой точки зрения о новом виде политики. В самом деле, движение, которое заставляет Рансьера погрузиться в педагогический опыт Жакото, с одной стороны, обнажает один из парадоксов образовательного учреждения (и, в частности, государства): что оно навязывает или должно навязывать (или до какой степени оно обязывает) во имя свободы. Таким образом, в центр анализа перемещается вопрос о пределах осуществления власти и потребности в подчинении (то, как действует государство через школу) в противовес 
объединению субъектов (свободных существ). С другой стороны, это обращает наше внимание на отсутствие того, кто должен объяснить, каким образом устроены вещи и что нужно делать; но также подчеркивается, что мы способны думать и делать. Неспособность прийти к чему-либо самостоятельно, как и структурообразующая симуляция, которая, как можно догадаться, закладывает объяснение в свое основание, - это та же неспособность для проведении политики делегирования. Именем технической или операционной неспособности (незнания и/или неспособности самостоятельно принимать решения) находит себе оправдание потребность в посредниках: экономических технократах, «профессиональных» политиках и т. д. Парадокс эмансипирующего учителя состоит в том, что он освобождает, не считая себя лидером или проводником, он делает это, понимая, что каждый способен это сделать. Можно пойти еще дальше. Объяснение - это не просто оружие отупления, которое наивно используют педагоги, но по сути само структурирование социального порядка: доминирующим объяснением является то, которое «объясняет» - явно или неявно - причину распределения существующих слоев общества и необходимости поддержания этого строя для общего блага. Расстояния, которые школа (и государство) намеревается сократить, - это то, чем она живет и что придает ей смысл, а следовательно, она не перестает их воспроизводить. В конечном итоге интеграция социальных связей гарантируется безропотной интеграцией масс под руководством образованных элит. Дерзость или притязание намека на то, что можно «научить тому, чего не знаешь», имеет гораздо больше решающего философского и политического намерения, чем выражение дидактического абсурда, поскольку выражает силу мысли и саму возможность, которой обладает каждый, построить нечто новое.

Ничто из этого не было бы возможным без основополагающего предположения, что мы все равны, что, по мнению Рансьера, представляет собой новую, неизвестную доныне радикальность. Но что это значит и каков диапазон этого утверждения?

Как это было упомянуто выше, равенство не будет чем-то, что находится в конце пути, как отдаленная цель, которую нужно достичь, и для которой важно только обсудить и оценить методы ее достижения. Для Рансьера равенство - это утверждение, не имеющее никакого другого основания, кроме решения его достичь и воли, чтобы следовать этому решению. Таким образом, размещение равенства в начале определяет отправную точку для всех человеческих действий и действительно освобождающего мышления.

У Жакото тема равенства сосредоточена на равенстве интеллектов, и Рансьер берет в этом равенстве свое основание, использует и расширяет его до общего плана. В этом движении мы снова видим, как формируется переход от педагогического к политическому. Решение начать с равенства, пусть и не подтвержденного, тем не менее содержит ряд комментариев или иллюстраций, которые служат своего рода оправданием. В самом деле, Рансьер делает паузу, чтобы обсудить тривиальный эмпирический вывод о том, что действительно существует, - это неравенство. Фактически нигде вы не увидите ничего, кроме неравенства интеллекта или просто неравенства. Что может быть более 
естественным, чем проверить доказательства, которые может подтвердить любой: существуют умные и глупые, способные и неспособные, открытые души и закостенелый мозг. Некоторые сдают экзамены лучше, чем другие; одни прогрессируют, другие только повторяют независимо от того, являются ли они представителями одного или же различных социального, культурного и прочих происхождений. Одни знают, другие нет. Одни могут, другие нет. Но что можно извлечь во имя политики или в пользу справедливости, убедившись в том, что все мы разные? Разве нельзя также утверждать, что равенство господина и слуги или властвующего и подчиненного очевидно, поскольку «очевидно», что последний должен «понимать» приказы первого, чтобы подчиняться им? Разве это не тот же интеллект, который заставляет их встраивать себя в одну и единую структуру господства? По мнению Рансьера, всякий, кто хочет исходить из неравенства, должен предполагать равенство, и в этом он поддерживает решение, которым руководствуется книга.

Образование и политика не могут начинать с неравенства и пытаться свести его на нет корректирующими действиями - образовательными или политическими, которые стремятся сделать равных из неравных. Тот, кто начинает с неравенства, которое он понимает на самом деле, очевидно, признает его. Это означает, что он признает, что либо для него существуют неравные (низшие) и он стремится уравнять их (делая все возможное, чтобы «подняться» к низшим); либо, что для него существуют другие неравные (высшие), которых он должен стремиться уравнять, но непосредственно с их помощью (иначе, очевидно, они не были для него высшими и, следовательно, он мог бы оставаться самодостаточным). В любом случае то, что доминирует - и это матрица политического прочтения, которую конструирует «Невежественный наставник» - это презрение: либо к другому, либо к самому себе [1]. Это желание основать каждую попытку действия на бессилии, слабости или худшего в каждом.

Что интересует Рансьера, так это раскрыть потенциал каждого человека, когда он считает себя равным другим и считает всех людей равными себе. Воля будет возвращением к самому себе того существа, которое рассуждает и признает себя способным думать и действовать. Признание равенства переводит властные отношения в горизонтальную плоскость и отводит ведущую роль каждому из нас. Это способ установления отношений между людьми, в котором для всех без исключения признается достоинство речи, то есть того, что они разделяют между собой. То, что отупляет человека, - это не недостаток образования, но вера в неполноценность собственного интеллекта. И то, что отупляет «низших», в то же самое время отупляет и «высших».

В этом ключе то, что действительно освобождает, будет не путешествием или путем к достижению равенства (которое в конечном счете никогда не реализуется полностью), но признанием принципа. Равенство не дается и не утверждается, оно практикуется, учит нас Рансьер. И Жакото показывает нам, что даже самые «невежественные» тоже многое знают, и любой вид обучения должен основываться на этом. В таком случае преподавание будет означать либо отупление, то есть постоянное подтверждение неспособности в попытках 
сократить дистанцию с незнанием; либо освобождение, то есть принуждение существующей способности, которая игнорируется или отрицается, к тому, что нужно извлечь из учения все возможные результаты.

С большой проницательностью Рансьер помещает центр внимания в другое место и устраняет это противопоставление. В этом изменении точки зрения учителя (и все люди в целом) не освобождают или подчиняют, следуя своей единственной функции в институциональном дизайне государства, но делают это на основании своих решений относительно отношений, которые они устанавливают с другими. Освободительное действие будет следствием поддержки тезиса о равенстве между людьми, и благодаря этому решению, откроется мир беспрецедентных возможностей, в котором обладание знаниями не будет завуалированным основанием иерархий. Это послание, которое дает нам «Невежественный наставник». Но это также открывает двери для других проблем.

Так, книга Рансьера ломает в общем смысле понятие «жертва» (системы, условий производства и воспроизводства, структурной бедности, глобализации и т. д.), поскольку предполагаемая жертва - это тот, кто думает и решает, а не просто тело, которое нужно кормить, или невежественное существо, которое нужно воспитывать. Концептуальное признание неравенства по происхождению заключается в том, что жертва не может привести дальше, чем к состраданию, к благочестивому чувству милосердия. И это потому, что другой считается не равным, а подчиненным, которому нужно помогать. Напротив, другой для Рансьера, - это тот, кто мыслит, и в эгалитарном диалоге разумных существ он способен показать, что «невежественный» может стать освободителем, а мудрец - тем, кто отупляет. Мы можем сделать вывод, который для многих может быть удивительным: равенство зависит не от социального (это даже не результат справедливого действия), но от решения и от того, насколько оно ему соответствует. Кроме того, «Невежественный наставник» также позволяет увидеть еще одну своеобразную идею: равенство исключено из нормального функционирования всякого социального порядка, но оно, в свою очередь, является его оправданием и целью (оно вынесено за пределы и в конечном итоге недостижимо). И этот контрапункт также важен в образовании: всегда есть то, о чем стоит умолчать, чтобы образование было возможным.

\section{Заключение}

Подводя итоги проведенному исследованию, можно указать на то, что книга Рансьера выходит далеко за границы сугубо педагогического опыта Жакото. Развивая спираль собственного анализа, автор «Невежественного наставника» демонстрирует не столько парадокс образовательной системы, которая под маской обучения подавляет внутренний потенциал ученика, навязывая ему посредством объяснений неравные отношения с хранителями знаний (эксперты, учителя), но сколько обнажает перед нами уязвимость самой этой системы от разоблачения ее при помощи формулы «ты можешь», которая выступает ключом к двери самостоятельного познания или, говоря языком Рансьера - Жакото, «отправляет вас в интеллектуальное путешествие» [1]. 
Расширяя в ходе своего анализа тезис об интеллектуальном равенстве, Рансьер не просто переносит своего читателя в область политического, но также, добавляя элемент воли, указывает на важность действия как в образовательной, так и в общественной сферах с целью разрыва с устоявшейся и самовоспроизводящейся моделью социальных отношений. И такого рода акцент позволяет перенести аналитические находки Рансьера совершенно в иную плоскость - в современный цифровой контекст, тем самым придавая спирали его исследования новый виток и продолжая углублять затронутую им проблематику.

Цифровое поле информации и цифровая культура подобно либертарным выводам Рансьера - Жакото ставят под сомнение идею власти: того, кто и как производит и передает знания. Пользователи интернета призваны стать производителями технологий и знаний, но также и преобразующими агентами сети в целом. Таким образом, «знания - это не то, что усваивает учащийся, а то, что он создает» [12], подобно тому как ученики Жакото самостоятельно постигали грамматику французского языка.

Разумеется, обучение, основанное на действии, на творчестве, неизбежно является обучением, обреченным на ошибки и потери, но в то же время это свободное и смелое обучение, которое рассматривает ошибки как еще одну форму получения знаний. Следовательно, наделение ценностью ошибки как формы обучения, ориентация на действие вопреки чисто теоретическими размышлениями, экспериментирование и разработка жизнеспособных прототипов - принципы, на которых основываются современные методологии, такие как дизайн-мышление (Design Thinking), вполне соотносятся с автономным и творческим обучением, которое Жакото защищает в своем универсальном учении, что в очередной раз делает его революционный опыт актуальным для современности.

\section{Лuтература}

1. Rancière J. Le maitre ignorant, Paris: Fayard, 1987.240 p.

2. Jacotot J. Enseñanza universal. Lengua Materna. Buenos Aires: Cactus, 2008. 316 p. URL: https://www.uv.mx/personal/jmercon/files/2011/08/Jacotot_Lengua_Materna.pdf (дата обращения: 03.03.2021).

3. Marina JA. El misterio de la voluntad perdida. Barcelona: Anagrama, 1997. 328 p. Текст: непосредственный.

4. Biesta G. Aprendiz, estudiante, hablante. Por qué importa cómo llamamos a quiénes enseñamos // Jacques Rancière. La educación pública y la domesticación de la democracia / G. Cornelisen, J. Larrosa Bondía y J. Masschelein (eds.) Buenos Aires: Miño y Dávila Editores, 2011. P. $149-176$.

5. Simmons M., Masschelein J. y Larrosa J. (eds.). Jacques Rancière. La educación pública y la domesticación de la democracia. Buenos Aires: Miño y Dávila Editores, 2011. 352 p.

6. Freire P. Pedagogía de la Autonomía. Sao Paulo: Paz e Tierra, 2004. 136 p. URL: https://redclade.org/wp-content/uploads/Pedagog\%C3\%ADa-de-la-Autonom\%C3\%ADa.pdf (дата обращения: 07.03.2021).

7. Illich I. La sociedad desescolarizada. México: Editorial Joaquín Moritz, 1985. URL: http://www.mundolibertario.org/archivos/documentos/IvnIllich_lasociedaddesescolarizada.pdf (дата обращения: 15.02.2021).

8. Holt J. Instead of education: Ways to help people do things better. Boulder: Sentient Publications, 2004. 250 p. 
9. Piaget J. El criterio moral en el niño. Barcelona: Martínez Roca, 1984. 358 p.

10. Cerletti A. A. La politique du maître ignorant : la leçon de Rancière // Le Télémaque. Caen: Presses universitaires de Caen, num. 27, 2005. P. 81-88. URL: https://www.cairn.info/revuele-telemaque-2005-1-page-81.htm (дата обращения: 26.02.2021).

11. Romero Frías E. y Magro Mazo C. La emancipación intelectual en la sociedad digital: El maestro ignorante de Rancière en nuestros días // Letral, n. 16, 2016, pp. 89-105. URL: https://www.researchgate.net/publication/304170142_La_emancipacion_intelectual_en_la_sociedad digital El maestro ignorante de Ranciere en nuestros_dias (дата обращения: $\overline{15} .0 \overline{3} .2021$ ).

12. Couros G. Create, Innovate, and Vo-̄ce. Дата публикации: 11 сентября 2012. URL: http://georgecouros.ca/blog/archives/3528 (дата обращения: 01.03.2021). T

Статья поступила в редакцию 23.04.2021; одобрена после рещензирования 30.04.2021; принята к публикации 11.05.2011.

\title{
POLICY AND A METHOD OF INTELLECTUAL EMANCIPATION
}

\author{
Aleksandr A. Vlasov \\ Research Assistant, \\ Russian State University for the Humanities, \\ 6 Miusskaya Square, Moscow 125993, Russia \\ mioxin@gmail.com
}

Abstract. The article analyzes Jacques Rancière's work "Le Maître ignorant : Cinq leçons sur l'émancipation intellectuelle", where the author refers to the educational experience of a French teacher Joseph Jacotot. In his work, Rancière not only criticize the methods of traditional education, but going beyond a purely pedagogical dimension he develops Jacotot's ideas and transfers them to the sphere of social and political relations, revealing that not only the school reproduces student's dependent position from a teacher, but also the State by means of the conventional strategy of education supports an established social order, negating the individual potential of each citizen (just like a "competent" mentor does it with an "uneducated" student by means of "explanation").

In his provocative criticism Rancière (together with Jacotto) tries to demonstrate the possibility of a different kind of relationship between teacher and student, when each of them is at an equal distance from the source of knowledge. And revealing the potential of the "ignorant" mentor, Rancière strives to reach a new level of relationships between them by comprehending the society within which these moral agents operate.

Keywords: Rancière, Jacotot, pedagogy of liberation, universal training, public order, the State

For citation

Vlasov A. A. Policy and A Method of Intellectual Emancipation. Bulletin of Buryat State University. Philosophy. 2021; 2: 48-60 (In Russ.).

The article was submitted 23.04.2021; approved after reviewing 30.04.2021; accepted for publication 11.05.2021. 